\title{
BMJ Open Uterine balloon tamponade as an adjunct to misoprostol for the treatment of uncontrolled postpartum haemorrhage: a randomised controlled trial in Benin and Mali
}

\author{
Alexandre Dumont, ${ }^{1}$ Cécile Bodin, ${ }^{1,2}$ Benjamin Hounkpatin, ${ }^{3}$ Thomas Popowski, ${ }^{4}$ \\ Mamadou Traoré, ${ }^{5}$ René Perrin, ${ }^{3}$ Patrick Rozenberg ${ }^{6}$
}

To cite: Dumont A, Bodin C, Hounkpatin B, et al. Uterine balloon tamponade as an adjunct to misoprostol for the treatment of uncontrolled postpartum haemorrhage: a randomised controlled trial in Benin and Mali. BMJ Open 2017;7:e016590. doi:10.1136/ bmjopen-2017-016590

- Prepublication history for this paper is available online. To view these files please visit the journal online (http://dx.doi. org/10.1136/bmjopen-2017016590).

Received 26 February 2017 Revised 30 June 2017 Accepted 5 July 2017

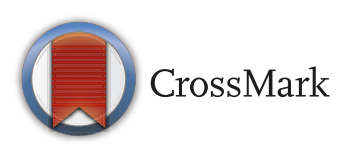

For numbered affiliations see end of article.

Correspondence to Dr Alexandre Dumont; alexandre.dumont@ird.fr

\section{ABSTRACT}

Objective To assess the effectiveness of low-cost uterine tamponade as an adjunct to misoprostol for the treatment of uncontrolled postpartum haemorrhage (PPH) in lowresource settings.

Design Randomised controlled trial.

Setting Seven healthcare facilities in Cotonou, Benin and Bamako, Mali.

Population Women delivering vaginally who had clinically diagnosed PPH that was suspected to be due to uterine atony, who were unresponsive to oxytocin and who needed additional uterotonics.

Methods Women were randomly assigned to receive uterine balloon tamponade with a condom-catheter device or no tamponade; both groups were also given intrarectal or sublingual misoprostol.

Main outcome measure Proportion of women with invasive surgery or who died before hospital discharge. Results The proportion of primary composite outcome did not differ significantly between the tamponade arm (16\%; 9/57) and the standard second line treatment arm (7\%; 4/59): relative risk 2.33 (95\% Cl 0.76 to 7.14 , $p=0.238)$. A significantly increased proportion of women with tamponade and misoprostol versus misoprostol alone had total blood loss more than $1000 \mathrm{~mL}$ : relative risk 1.52 (95\% Cl 1.15 to $2.00, p=0.01)$. Case fatality rate was higher in the tamponade group $(10 \% ; 6 / 57)$ than in the control group ( $2 \% ; 1 / 59)(p=0.059)$.

Trial registration number ISRCT Registry Number 01202389; Post-results.

\section{INTRODUCTION}

Postpartum haemorrhage (PPH) remains one of the leading causes of global maternal morbidity and mortality. ${ }^{1}$ Despite active management of the third stage of labour, an effective strategy to reduce the risk of this complication among uncomplicated births, between $2 \%$ and $7 \%$ of women still have primary blood loss more than $500 \mathrm{~mL}$ at the time of birth. ${ }^{2}$ Uterine atony is the most common cause of PPH in the world and one
Strengths and limitations of this study

- This study is the first randomised controlled trial to test the effectiveness of uterine balloon tamponade (UBT) by condom-catheter device as an adjunct to misoprostol for the treatment of the postpartum haemorrhage.

- This study was realised in real condition of medical care in order to test the real interest of this treatment. Only misoprostol, UBT kit and training were provided to health workers.

- Because of a lower than expected incidence of the primary outcome in the control group, the study was underpowered.

- The observance of the research protocol was not optimal in the experimental group. Some patients did not receive the UBT.

- PPH management was suboptimal in both groups with frequent delays observed in diagnosis and treatment of uterine atony.

of the major causes of maternal mortality in low-income countries, although effective treatments are known. ${ }^{3}$ Indeed, oxytocin infusion is regarded as the gold standard for the treatment of uterine atony. ${ }^{4}$

If the oxytocin fails to control the bleeding, there is a lack of data concerning the recommendations for the therapies of second line to be implemented for the treatment of uncontrolled PPH before recourse to the invasive surgeries. According to the WHO, 'decisions in such situations must be guided by the experience of the provider, the availability of the drugs and by known contraindications' ${ }^{5}$ In low-resource settings, the misoprostol has several advantages because it is easy to store at room temperature, of low cost and relatively safe. ${ }^{3}$ The level of proofs concerning the efficiency of the misoprostol in the treatment of uncontrolled PPH is weak, ${ }^{67}$ and findings 
from one randomised trial do not support clinical use of sublingual misoprostol in addition to standard injectable uterotonics for treatment of $\mathrm{PPH}^{8}{ }^{8}$ Nevertheless, the misoprostol is being incorporated in many clinical services in sub-Saharan Africa and providers are using it to stop PPH which is not controlled by the oxytocin. Among other potentially effective second line of treatments in this context, uterine balloon tamponade (UBT) with condom-catheter as a supplement to uterotonics is an attractive option because it is easy to use, not invasive and ultra-low-cost as compared with other devices used in high-income countries. ${ }^{9}$ However, this approach has not yet undergone rigorous evaluation, and according to WHO, research on this subject should be a priority. ${ }^{5}$

We designed a randomised controlled trial in Benin and Mali evaluating the effectiveness of the condom-catheter UBT as a supplement to the misoprostol for the management of uncontrolled PPH. We hypothesised that the UBT combined with misoprostol was more effective than the misoprostol alone to stop haemorrhage and to prevent severe maternal morbidity.

\section{METHODS}

This trial was a multicentre randomised controlled trial with two parallel groups. It took place in seven healthcare facilities in Cotonou, Benin (one mid-level community health facility, two districts hospitals and one teaching hospital) and Bamako, Mali (two mid-level community health facilities and one tertiary hospital) between May 2013 and December 2015. The recruitment period and follow-up took place from 14 October 2013 to 31 December 2015. It was registered at ISRCT with the following number: 01202389.

Active management of the third stage of labour was presumably systematically performed in all centres. Since the use of collection bag is not a common practice in Benin and Mali, PPH was clinically assessed by the caregivers (midwife or doctor) according to the visual estimation of excessive blood loss and patient status (blood pressure and cardiac frequency). The first-line treatment of $\mathrm{PPH}$, based on the recommendations of the African Society of Gynaecology and Obstetrics, ${ }^{10}$ included uterine massage and intravenous or intramuscular oxytocin. PPH was defined as uncontrolled if active bleeds did not cease 20 min after the beginning of the initial treatment.

Patients managed in primary healthcare facilities but requiring more specialised care (ie, blood transfusion, intensive care unit or surgery) were referred to district or tertiary hospitals. In these hospitals, a gynaecologist obstetrician and an anaesthesiologist were on call 24 hours a day. Before the trial started, all health professionals of the participating centres were trained to the use of UBT with the condom-catheter device (half day in-site training). Given frequent turnover of the staff, these training sessions were offered between two and three times in each participating centre during the study period. Tablets of $200 \mu \mathrm{g}$ misoprostol and UBT kits (including Foley catheter size
24, condom, 1-litre bag of solute, needleless suture, $50 \mathrm{~mL}$ syringe, compresses, sterile gloves) were implemented in the participating centres (each kit costing US $\$ 10$ but free of charge for the patients) and regularly checked and stocked by the local trial supervisor.

\section{Participants}

Women having given birth vaginally and presenting a $\mathrm{PPH}$, suspected to be due to a uterine atony and resistant to the first-line treatment (oxytocin) were included in the participating centres. We excluded women who had a known contraindication to prostaglandins, a uterine rupture or a placenta accreta. Women with retained placenta were not excluded. Women were provided with information about the trial during antenatal consultation and at the time of PPH diagnosis. Due to the emergency of the PPH, all women involved in the trial provided an oral consent just before randomisation and a written consent in postpartum period after the bleeds ceased. In the event of death, a written consent was asked to the members of his family.

\section{Patient involvement}

No patient was involved in the elaboration of the research questions or the outcomes measures. They do not have either been involved in developing plans for recruitment, design or implementation of the study. No patient was involved in the interpretation or the writing of the results. There are no plans for the dissemination of the results of research to the participants or to patient organisations.

\section{Interventions}

We compared the UBT combined with misoprostol to misoprostol alone. In both groups, the misoprostol was administered in the rectum $(1000 \mu \mathrm{g})$ or under the tongue $(600 \mu \mathrm{g})$ just after randomisation and after manual removal of the placenta for women with retained placenta. In the intervention arm, a condom was placed over a Foley catheter and secured by a suture. The catheter was introduced into the uterus, and the condom was inflated by increments of $250 \mathrm{~mL}$ of solute without exceeding $1000 \mathrm{~mL}$.

After each increment was added, if bleedings continued after $5 \mathrm{~min}$, the clinician continued filling the condom until the maximum level was reached. Once the bleedings were stopped, compresses were placed on the vaginal fornix to prevent accidental removal of the condom, and the Foley catheter was clamped. The condom-catheter device was then held in place for at least 6 hours. The removal of the condom-catheter device began by emptying half of the solution initially injected. Then, it was completely removed 1 hour later. If the bleedings resumed, the condom catheter was reinflated and held in place for two more hours. In all cases, a single dose of cefazolin or ampicillin was administered as an antibiotic prophylaxis.

The sequence of events, from eligibility assessment, can be summarised as follows: if the bleedings continued 
20 min after the administration of first-line treatment by oxytocin, the woman was randomised, the misoprostol administered and the condom catheter inserted, according to group allocation. The treatment was considered as successful if the bleedings were controlled within $15 \mathrm{~min}$ after the intervention. If the bleeding was not controlled within $15 \mathrm{~min}$, immediate surgery was recommended.

\section{Outcomes}

The primary outcome is a composite outcome. It corresponds to the proportion of women with recourse to an invasive surgery (arterial ligatures, uterine compressive sutures, hysterectomy) or who died before hospital discharge. The secondary outcomes were each component of the composite outcome and also total blood loss more than $1000 \mathrm{~mL}$, blood transfusion and transfer to intensive care unit. The women were called by phone within 15 days after hospital discharge in order to get information about the postpartum period at home and the possible adverse events arisen since discharge. Each maternal death was audited by two independent experts in order to assess if the event was possibly due to the experimental treatment or not. The case report forms on paper were regularly controlled for data quality by the data manager (CB) and entered using double data entry by researchers onto a computer database. An independent data security and monitoring board did one planned blinded interim analysis when $50 \%$ of the number of needed subjects was attained. Based on the results, the DSMB recommended continuing with the recruitment for this study.

\section{Sample size}

On the basis of two descriptive studies, ${ }^{6} 7$ we assumed that misoprostol would fail to stop the bleedings in $25 \%$ of uncontrolled PPH cases. The formula of calculation applied to determine the required number of patient is the one used for the individual randomised controlled trials. This calculation was based on a conservative estimate of the reduction of the primary outcome of $75 \%,{ }^{9}$ which represents a decrease of the primary outcome from $25 \%$ in the control group to $6 \%$ in the intervention group. Taking into account a 5\% significance level with a $80 \%$ power in bilateral formulation, we should need to include 51 women in each group, so at least 102 women with uncontrolled PPH.

\section{Randomisation}

A computer-generated randomisation sequence was generated by the principal investigator $(\mathrm{AD})$ and stratified by health centre. Within the strata, women with PPH which was not controlled by the first-line therapy were individually allocated by blocks randomisation (varying blocks of four and stratified by healthcare centre) to receive either the uterine tamponade associated with misoprostol or the misoprostol alone. The randomisation code was only known by the principal investigator (AD), the project manager $(\mathrm{CB})$ and both local trial supervisors (not involved in patients care) in Benin and Mali. The trial supervisor was called by phone by the caregiver (a midwife or a doctor) and he checked with her or him the inclusion and exclusion criteria. If the patient was eligible for the trial, she was randomised using the computer-generated randomisation sequence. If the patient was allocated in the tamponade and misoprostol group, the caregiver inserted the balloon catheter in theatre or on the wards, depending on the context. The uterine cavity was explored manually first to exclude retained products of conception. The condom catheter was inserted manually on the delivery suite using hands only. Then the compresses were placed at the bottom of vagina, in contact with the cervix and the balloon.

\section{Statistical analysis}

All analyses were performed by intention to treat. The comparisons between treatment groups for the baseline characteristics were done in order to ensure comparability between study groups. $\chi^{2}$ test, Fischer's test and Wilcoxon range test were done to assess the association between outcomes and treatments across the participating centres. The dichotomous data are presented as absolute value and percentage. The quantitative data were not distributed normally due to the low number of recruited women, so these data are presented as median value with IQR. Binary clinical outcomes are compared between groups with relative risks and corresponding 95\% CIs. All statistical analyses were done with STATA/IC V.12.1 and we judged $p$ values of less than 0.05 as significant.

\section{RESULTS}

Figure 1 shows the trial profile. A total of 444 women with $\mathrm{PPH}$ that was suspected to be due to uterine atony were assessed for eligibility. Eleven women were excluded because of a uterine rupture $(n=9)$ or a placenta accreta $(n=2)$, diagnosed before randomisation as a cause of the bleeds. Among the 433 remaining women, PPH was controlled by the first-line treatment by oxytocin in 317 $(73 \%)$ of cases. Finally, 116 women with uncontrolled PPH were allocated by the randomisation to the group misoprostol and tamponade $(\mathrm{n}=57)$ or to misoprostol alone $(n=59)$. No patients were lost from the randomisation to the final follow-up by phone, except seven women who died before hospital discharge (six women in the experimental arm and one woman in the control arm). For the 109 remaining women, no problem or side effects in the postpartum period were reported.

Baseline characteristics were similar for all the participants allocated to each study group (table 1). All women delivered vaginally without forceps or vacuum, but some of births were complicated (placental abruption, intrauterine death) or at increased risk for severe PPH (labour induced, labour augmented, multiple pregnancy). Two-thirds of women included in the trial were randomised in tertiary hospitals. 


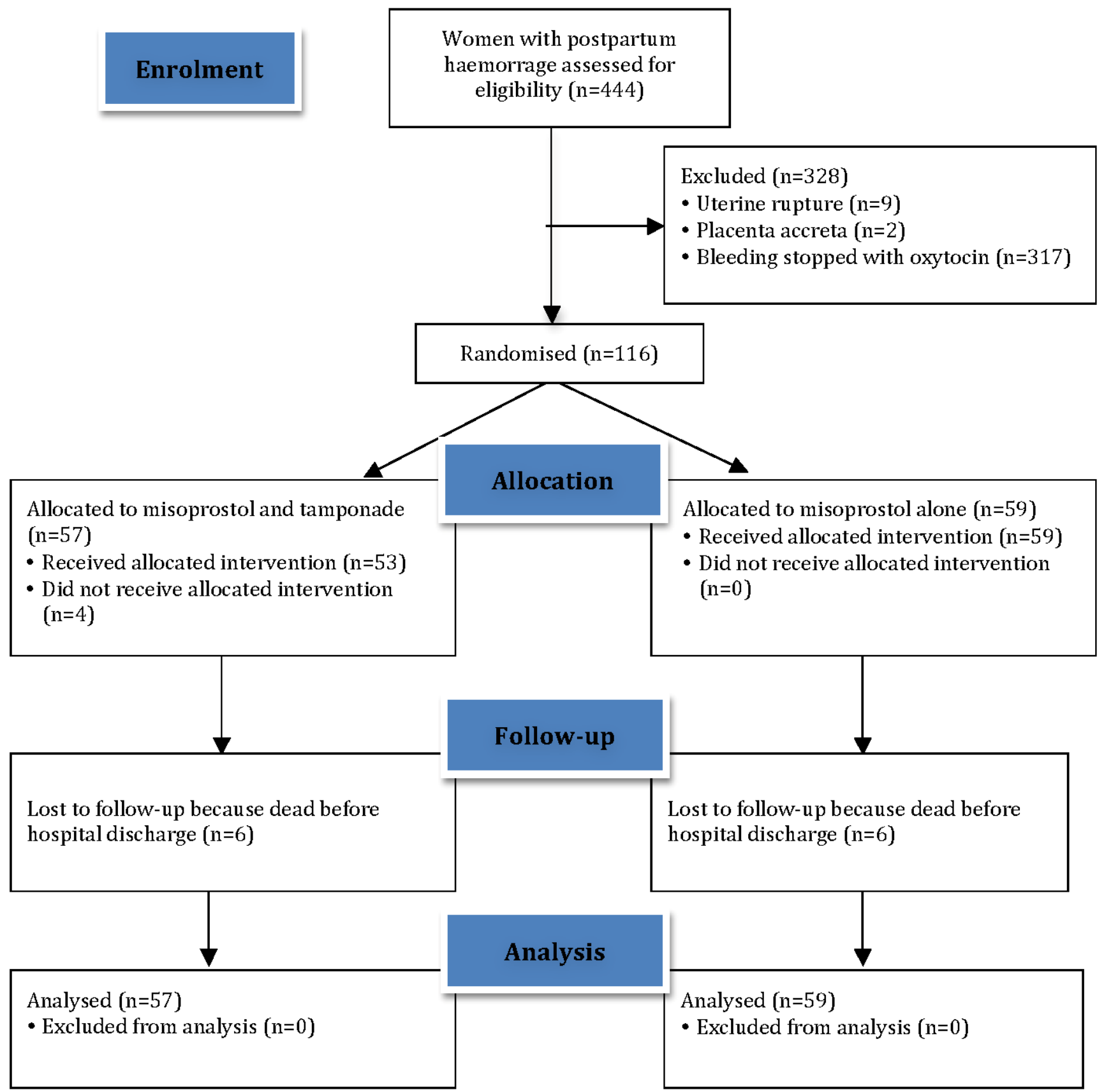

Figure 1 Study flow diagram.

Delays in the different steps of the diagnosis and/or the treatment of the PPH were frequent in both groups. Uterine atony was diagnosed within $120 \mathrm{~min}$ after birth in $76 \%$ of the cases. The oxytocin for the PPH treatment was administered late (more than 10 min after diagnosis time) to $23 \%$ of women, who therefore did not receive the recommended care for the first-line of treatment of PPH.

Among 57 patients allocated to the misoprostol and tamponadearm, twowomen did notreceive the condom-catheter device because they died before the procedure. Moreover, two women did not benefit of the tamponade because staff decided to postpone the treatment for unknown reasons (table 2). For 53 women who received the allocated intervention, the median volume of solute inflated in the condom was $500 \mathrm{~mL}$ (IQR from 400 to $600 \mathrm{~mL}$ ). The rupture or the premature expulsion of the condom occurred in two cases without recovery of the bleedings or further complications. For the 51 remaining patients, the length of time between the insertion of the condom-catheter and the removal ranged from 4 to 19 hours. All women received misoprostol in both groups, mostly using intrarectal administration. However, the second line of treatment by uterotonic was administered late (more than $30 \mathrm{~min}$ after $\mathrm{PPH}$ diagnosis) to $54 \%$ of the women in the tamponade and misoprostol arm and to $37 \%$ of the women in the misoprostol arm (table 2). 
Table 1 Baseline characteristics of participants

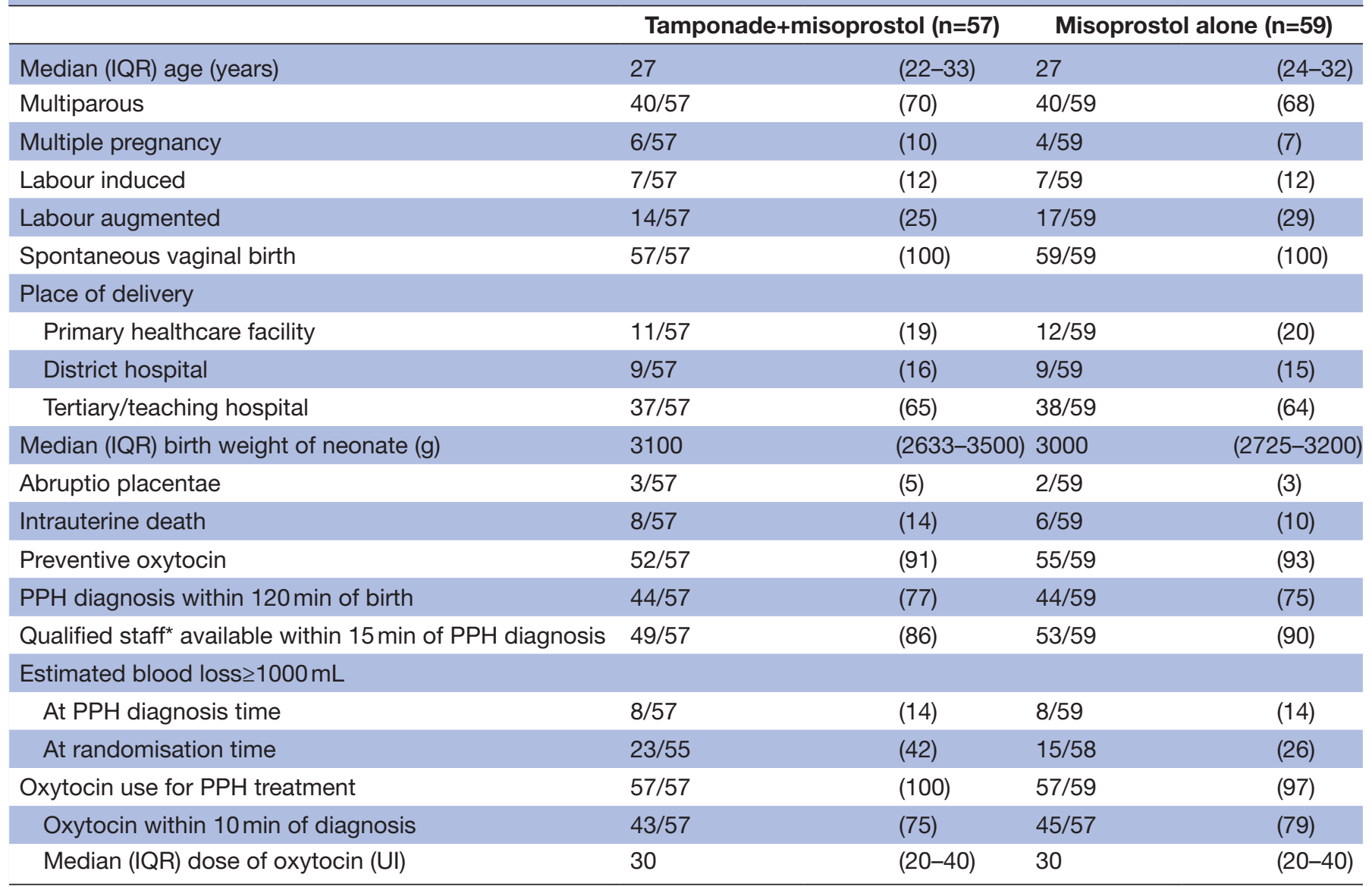

Values are number with characteristic/number in group (percentage) unless stated otherwise.

${ }^{*}$ At least one doctor and one midwife.

$\mathrm{PPH}$, postpartum haemorrhage; IU, international unit.

The proportion of women who needed a manual removal of the placental or products of conception was higher in the intervention group (19\%) than in the control group $(10 \%)$. Other treatments (suture of cervical, vaginal or perineal tears, provision of fluids or plasma expanders, antibiotics or tranexamic acid) were similar in both groups.

Analysis of the primary outcome (table 3) showed that the proportion of women with invasive surgery or who died before hospital discharge did not differ significantly between the intervention group $(16 \% ; 9 / 57)$ and the control group $(7 \% ; 4 / 59)$-relative risk 2.33 (95\% CI 0.76 to $7.14, \mathrm{p}=0.238$ ). An increased proportion of women with tamponade and misoprostol versus misoprostol alone have lost more than $1000 \mathrm{~mL}$ of blood (estimated on the basis of the clinical judgement of the health provider)relative risk $1.52(95 \%$ CI 1.15 to $2.00, \mathrm{p}<0.001)$ and needed blood transfusion before discharge-relative risk 1.49 (95\% CI 0.88 to $2.51, \mathrm{p}=0.170)$. We did not observe any severe side effects related to misoprostol or intrauterine tamponade as reported in the literature: severe shivering, diarrhoea, vomiting or high temperature. ${ }^{8}$

Seven women died before hospital discharge: six patients with tamponade and misoprostol and one patient with misoprostol alone (table 3). The bleedings of four women, who were diagnosed with severe $\mathrm{PPH}$, did not cease after the tamponade. Among these maternal deaths, the misoprostol was administrated with the total dose of $1400 \mu \mathrm{g}(400 \mu \mathrm{g}$ intravaginal for labour induction and $1000 \mu \mathrm{g}$ intrarectal for PPH treatment) in two cases. For another case, intrarectal misoprostol was administered with the total dose of $1000 \mu \mathrm{g}$. Misoprostol was administered under the tongue with the total dose of $600 \mu \mathrm{g}$ for one case. In case 1 , the insertion of the condom-catheter device was late (2hours after randomisation) and did not control PPH. The patient died before she was transferred to the operating theatre. In case 2 , the condom-catheter device fell out twice of the uterus and the decision for the realisation of a laparotomy was delayed. The patient died during the surgery. In case 3, a hysterectomy was performed timely after the doctor observed that the tamponade failed to stop the bleedings. The patient died in the intensive care unit despite circulatory support and further blood transfusions. In case 4, the bleedings have resumed on withdrawal of the condom-catheter 10 hours after the insertion time. The patient died because of a disseminated intravascular coagulopathy, while blood products were not available. Two other women from the experimental group did not receive allocated intervention. In case 5 , the woman died from a massive haemorrhage within the 
Table 2 Adherence to allocated intervention and other aspects of management of postpartum haemorrhage

Tamponade+misoprostol

$(n=57)$
Misoprostol alone

$(n=59)$

\begin{tabular}{|c|c|c|c|c|}
\hline \multicolumn{5}{|l|}{ Allocated intervention } \\
\hline Misoprostol use & $57 / 57$ & (100) & $59 / 59$ & (100) \\
\hline $600 \mu g$ sublingual & $4 / 57$ & (7) & $6 / 59$ & $(10)$ \\
\hline $1000 \mu \mathrm{g}$ sublingual & $2 / 57$ & (3) & $1 / 59$ & $(2)$ \\
\hline $1000 \mu \mathrm{g}$ intrarectal & $50 / 57$ & (88) & $51 / 59$ & (86) \\
\hline $1000 \mu \mathrm{g}$ intrarectal and sublingual & 0 & & $1 / 59$ & (2) \\
\hline $2000 \mu \mathrm{g}$ intrarectal and sublingual & $1 / 57$ & (2) & 0 & \\
\hline Misoprostol within $30 \mathrm{~min}$ of PPH diagnosis & $26 / 56$ & (46) & $37 / 59$ & (63) \\
\hline UBT with condom catheter device & $53 / 57$ & (93) & - & \\
\hline UBT within 30 min of PPH diagnosis & $31 / 53$ & (58) & - & \\
\hline Median (IQR) volume of solute inflated in the condom $(\mathrm{mL})$ & 500 & $(400-600)$ & - & \\
\hline Median (IQR) time to UBT removal (hours) & 9 & $(4-14)$ & - & \\
\hline \multicolumn{5}{|l|}{ Other treatments } \\
\hline Manual removal of the placenta or products & $6 / 57$ & (10) & $10 / 59$ & $(17)$ \\
\hline Suturing cervical, vaginal or perineal tears & $17 / 57$ & (30) & $20 / 59$ & (34) \\
\hline Fluids and/or plasma expanders & $57 / 57$ & $(100)$ & $57 / 59$ & (97) \\
\hline Antibiotics & $15 / 57$ & (26) & $15 / 59$ & (25) \\
\hline Tranexamic acid & $3 / 57$ & (5) & $3 / 59$ & (5) \\
\hline
\end{tabular}

Values are number with variable/number in group (percentage) unless stated otherwise.

$\mathrm{PPH}$, postpartum haemorrhage; UBT, uterine balloon tamponade.

20 min after the randomisation, before the misoprostol was able to be administered and before the condom catheter could have been inserted. In case 6 , given the severity of the bleedings, the staff decided to postpone the treatment. A laparotomy was done just after the randomisation and before the misoprostol was able to be administered. Then, a hysterectomy was performed because of the placenta attached abnormally to the myometrium. The woman died during surgery and the final diagnosis was placenta accreta and not uterine atony. In case 7 in the control group, the patient died because of a disseminated intravascular coagulopathy despite transfusion of $200 \mathrm{~mL}$ of fresh frozen plasma and before the laparotomy was able to be performed. For this woman, the misoprostol was administered in the rectum with the total dose of $1000 \mu \mathrm{g}$.

\section{DISCUSSION}

The results of this trial does not show benefit for the UBT using the condom-catheter device in addition to the

Table 3 Trial outcomes

\begin{tabular}{|c|c|c|c|c|c|c|}
\hline & \multicolumn{2}{|c|}{$\begin{array}{l}\text { Tamponade+misoprostol } \\
(\mathrm{n}=57)\end{array}$} & \multicolumn{2}{|c|}{$\begin{array}{l}\text { Misoprostol } \\
\text { alone } \\
(n=59)\end{array}$} & \multirow[t]{2}{*}{$\begin{array}{l}\text { Relative risk } \\
(95 \% \mathrm{Cl})\end{array}$} & \multirow[t]{2}{*}{ p Value } \\
\hline \multicolumn{5}{|l|}{ Primary outcome } & & \\
\hline Recourse to invasive surgery or death & $9 / 57$ & (16) & $4 / 59$ & (7) & 2.33 (0.79 to 7.14$)$ & 0.238 \\
\hline \multicolumn{7}{|l|}{ Secondary outcomes } \\
\hline Hysterectomy & $4 / 57$ & (7) & $1 / 59$ & (2) & $4.14(0.48$ to 35.93$)$ & 0.203 \\
\hline Transfer to intensive care unit & $10 / 57$ & $(17)$ & $8 / 59$ & (14) & 1.29 (0.55 to 3.04$)$ & 0.614 \\
\hline Total blood loss more than $1000 \mathrm{~mL}$ & $43 / 54$ & (80) & $31 / 59$ & (52) & 1.52 (1.15 to 2.00$)$ & $<0.001$ \\
\hline Transfusion & $23 / 57$ & $(40)$ & $16 / 59$ & $(27)$ & 1.49 (0.88 to 2.51$)$ & 0.170 \\
\hline
\end{tabular}

Values are number with outcome/number in group (percentage) unless stated otherwise. 
misoprostol for the treatment of the uterine atony uncontrolled by the oxytocin.

\section{Strengths and weaknesses of the study}

Our study is the first randomised controlled trial to test the effectiveness of the UBT as an adjunct to the misoprostol for this indication. The condom-catheter device is tailored to low-resource settings because it is of low cost and easy to implement.

However, this trial is limited by several factors. First, our study has a small sample size although it is sufficient in order to detect a significant effect of the UBT according to our primary hypothesis. However, in the control group, the primary outcome was less frequent $(7 \%)$ than the $25 \%$ prediction on which the sample size calculation was based. This may have been because of the mode of delivery, the dose and route of administration of misoprostol which differed between the present trial and both descriptive studies on which we based our estimation. ${ }^{6} 7$ Our study was thus underpowered to detect a statistically significant reduction in the primary outcome. Second, observance of the research protocol was not optimal in the experimental group. Four women did not receive the condom-catheter device in the intervention arm, partly because the condition of the women deteriorated too quickly.

Thirdly, the initial PPH management was suboptimal in both groups. Despite our efforts in order to improve the availability of the tablets of misoprostol and the different components of the UBT device, we observed frequent delays in the diagnosis and the treatment of the uterine atony. A high proportion of women having received a late injection of oxytocin (for the first line of treatment) is associated with an increased risk of severe $\mathrm{PPH} .{ }^{11}{ }^{12}$ Moreover, suboptimal care was balanced between women in both groups. This balance ensured that the increased proportion of women with severe morbidity in the intervention group could not be attributed to a better quality of $\mathrm{PPH}$ management in the control group. Otherwise, delays in the second-line PPH management could explain the significantly increased blood loss over $1000 \mathrm{~mL}$ and the higher case-fatality rate in the misoprostol and tamponade group compared with the control group. Indeed, delay in the administration of misoprostol was more frequent in the experimental group (table 2). Moreover, the condom catheter was inserted $30 \mathrm{~min}$ and more after the diagnosis of PPH in $58 \%$ of the cases (table 2), despite our efforts in order to improve the availability of the different components of the UBT device. Among the four women who died after the UBT, no hysterectomy was performed in three cases while UBT device failed to stop the bleedings. Although this was not reported by both maternal death reviewers, the UBT may have delayed the decision to perform a hysterectomy. Finally, in the referral hospitals, a large part of the UBT and misoprostol was administered by the doctors to the operating theatre. However, the recurring unavailability of the theatre had an important consequence in the delays for the experimental group.
In the control group (misoprostol only), the misoprostol was always administered in delivery room.

\section{Comparison with other studies}

Tindell et al published in 2012 the results of a systematic review on the UBT for the treatment of PPH in low-resource settings. ${ }^{9}$ The authors found no randomised trials and 13 descriptive studies including a total of 241 women who received the UBT for the treatment of PPH. In eight reviewed studies where a condom-catheter device was used as an adjunct to uterotonics, successful management of PPH was reported in 188 of 193 women $(97 \%)$. The reported cause of PPH was the uterine atony, placenta praevia, placenta accreta and coagulopathy. The procedures used for the condom-catheter device in reviewed studies were similar to those of the present trial. Other published papers report comparable high rates of successful management of uncontrolled $\mathrm{PPH}$ with tamponade, either in low-income countries using a condom-catheter device ${ }^{13}$ or in high-income countries using the Bakri balloon or the Belfort-Dildy Obstetrical Tamponade System. ${ }^{14-16}$ But these descriptive studies failed to control for concurrent successful management with additional standard uterotonics.

The successful rate of the PPH management was lower in the present trial $(87 \% ; 46 / 53)$ than in previous aforementioned studies in low-resource settings $(97 \% ; 188 / 193){ }^{9}$ Variations could possibly be due to the small sample size or the design (observational studies) of these studies. It could also be compounded by the bias of publication from other studies with a small sample size and demonstrating results less optimistic, which have not been published.

\section{Implications for clinical practice}

The mechanism of action for the UBT device is unclear. To collapse the blood vessels inside the uterus, the pressure inside the balloon does not necessarily rise above the systemic pressure. ${ }^{17}$ This is the case if the volume of solute inflated in the condom is around $500 \mathrm{~mL}$. Some authors suggest that the mechanism of action of the UBT device may involve the tamponade effect and the release of natural prostaglandins..$^{9}$ One randomised controlled trial showed that the condom-catheter device is as effective as the Bakri balloon but requires a significantly little longer time to stop the bleedings. ${ }^{18}$ However, advanced maternal age and caesarean section are associated with lower success rates. ${ }^{19}$ The present trial does not exclude the possibility that the condom-catheter device could be effective in settings where access to surgery is more difficult than in capital cities as Cotonou or Bamako. Indeed, Burke et al implemented the condom-catheter device in 307 healthcare facilities, of which 292 were remote rural clinics or lower-mid-level community health facilities in Kenya, Sierra Leone, Nepal and Senegal and reported $95 \%$ all-cause survival rate among 201 women with UBT. ${ }^{13}$

The misoprostol, a prostaglandin E1 analogue, is an effective myometrial stimulant in the immediate postpartum. ${ }^{20}$ If there is evidence that the misoprostol provides no added 
benefit when it is given simultaneously with other injectable uterotonics drugs for the first-line treatment of $\mathrm{PPH}^{8}$ there is no randomised controlled trial in order to test the efficacy of the misoprostol as a second-line therapy. ${ }^{21}$ The present trial does not exclude the possibility that the misoprostol could be effective in the treatment of the uterine atony unresponsive to the oxytocin. Indeed, the bleeding was controlled in $93 \%$ of women in our trial, all of whom received misoprostol. However, as there was no control group who did not receive misoprostol, we cannot be sure in how many cases the bleeding would have ceased without misoprostol. This success rate is higher than those reported in previous descriptive studies (between $63 \%$ and $87 \%$ ). This variation may be explained by differences in dosage ( $400 \mu \mathrm{g}, 800 \mu \mathrm{g}$ or $1000 \mu \mathrm{g})$, mode of administration (oral, sublingual or rectal) and type of birth (vaginal or caesarean). On the other hand, our results could point out the potential deleterious effect of high dose of misoprostol. Indeed, five of the seven registered maternal deaths in this trial could be associated with high-dose misoprostol $(600 \mu \mathrm{g}$ and more), considering the results of the systematic review of Hofmeyer and colleagues published in the Bulletin of the WHO ${ }^{22}$ However, among these five women who died after the administration of misoprostol, no known side effects of the misoprostol as fever or shiving, was reported by clinicians. For this reason, it is not clear to attribute these deaths to the misoprostol.

\section{CONCLUSION}

In low-resource settings and urban context, where operating theatres are available, the use of condom-catheter UBT in addition to misoprostol has no significant effect on recourse to invasive surgery. However, delays in PPH management may explain increased maternal morbidity and mortality among women treated with tamponade and misoprostol. Further studies are needed to ascertain optimal approaches for the medical management of patients with uterine atony unresponsive to oxytocin.

\section{Author affiliations}

${ }^{1}$ Research Institute for Development, Université Paris Descartes, Paris, France ${ }^{2}$ Community of Practice QUAHOR, Quality of Care in Referral Hospitals, Paris, France ${ }^{3}$ Department of Obstetrics and Gynaecology, CHU-MEL, University Hospital for Mother and Child of Lagune, Cotonou, Benin

${ }^{4}$ Department of Obstetrics and Gynaecology, Poissy Saint Germain Hospital, Poissy, France

${ }^{5}$ Department of Obstetrics and Gynaecology, Referral Health Center of the Commune V, Bamako, Mali

${ }^{6}$ Department of Obstetric and Gynecology, Poissy Saint Germain Hospital, Poissy, France

Acknowledgements We thank the independent data monitoring committee chaired by Catherine Deneux-Tharaux from the INSERM U953, Epidemiologic Research in Perinatal, Women's, and Children's Health, Pierre et Marie Curie University, Paris, France; the women who participated in the trial; the staff from the participating maternity units for including women and the members of The Trial Study Group: Mamadou Kani Konate and Mamadou Traoré from MARIKANI, Bamako, Mali; Jean-Claude Sagbo from the CHU-MEL, Cotonou, Benin.

Contributors AD participated in the design of the study, obtained funding, participated in the central monitoring of data collection, supervised the cleaning, analysis and interpretation of the data and the drafting and revision of the paper and had seen and approved the final version. He had full access to all of the data in the study and takes responsibility for the integrity of the data and the accuracy of the data analysis. CB participated in the design of the study, supervised the central monitoring of data collection, the cleaning and analysis of the data, participated in the drafting and revision of the paper and has seen and approved the final version. $\mathrm{BH}, \mathrm{RP}$ and MT participated in the design of the study, supervised the inclusion of women and the running of the trial in participating healthcare facilities, participated in the revision of the paper and had seen and approved the final version. TP participated in the design of the study, in the training of healthcare professionals in participating healthcare facilities, in the revision of the paper and had seen and approved the final version. PR participated in the design of the study, supervised the analysis and interpretation of the data, participated in the revision of the paper and had seen and approved the final version. $A D$ and $C B$ are guarantors for the paper.

Funding Research Institute for Development (IRD) and United Nations Children's Fund (UNICEF).

Competing interests All authors have completed the ICMJE uniform disclosure form at http://www.icmje.org/coi_disclosure.pdf (available on request from the corresponding author) and declare no relationships or activities that could appear to have influenced the submitted work. The head author (AD) affirms that the manuscript is an honest, accurate and transparent account of the study being reported; that no important aspects of the study have been omitted and that there are any discrepancies from the study as registered. AD has nothing to disclose.

Patient consent Obtained.

Ethics approval Ethics Committee of the Faculty of Medicine, Pharmacy and Odonto-Stomatology of Mali; Ethics and Research Committee of the Institute of the Biomedical Applied Sciences of Benin; Ethic Committee of the Research Institute for Development of France.

Provenance and peer review Not commissioned; externally peer reviewed.

Open Access This is an Open Access article distributed in accordance with the Creative Commons Attribution Non Commercial (CC BY-NC 4.0) license, which permits others to distribute, remix, adapt, build upon this work non-commercially, and license their derivative works on different terms, provided the original work is properly cited and the use is non-commercial. See: http://creativecommons.org/ licenses/by-nc/4.0/

(C) Article author(s) (or their employer(s) unless otherwise stated in the text of the article) 2017. All rights reserved. No commercial use is permitted unless otherwise expressly granted.

\section{REFERENCES}

1. Graham W, Woodd S, Byass P, et al. Diversity and divergence: the dynamic burden of poor maternal health. Lancet 2016;388:2164-75.

2. Begley CM, Gyte GM, Devane D, et al. Active versus expectant management for women in the third stage of labour. Cochrane Database Syst Rev 2015;2:CD007412.

3. Lalonde A. FIGO Safe Motherhood and Newborn Health (SMNH) Committee. Prevention and treatment of postpartum hemorrhage in low-resource settings. Int J Gynecol Obstet 2012;117:108-18.

4. Mousa HA, Blum J, Abou El Senoun G, et al. Treatment for primary postpartum haemorrhage. Cochrane Database Syst Rev 2014;13:CD003249.

5. World Health Organization. WHO recommendations for the prevention and treatment of postpartum haemorrhage. 2012. http:// apps.who.int/iris/bitstream/10665/75411/1/9789241548502_eng. pdf

6. Shojai R, Desbrière R, Dhifallah $\mathrm{S}$, et al. [Rectal misoprostol for postpartum hemorrhage]. Gynecol Obstet Fertil 2004;32:703-7.

7. Baruah M, Cohn GM. Efficacy of rectal misoprostol as second-line therapy for the treatment of primary postpartum hemorrhage. $J$ Reprod Med 2008;53:203-6.

8. Widmer M, Blum J, Hofmeyr GJ, et al. Misoprostol as an adjunct to standard uterotonics for treatment of post-partum haemorrhage: a multicentre, double-blind randomised trial. Lancet 2010;375:1808-13

9. Tindell K, Garfinkel R, Abu-Haydar E, et al. Uterine balloon tamponade for the treatment of postpartum haemorrhage in resource-poor settings: a systematic review. BJOG 2013;120.

10. Bureau régional de l'OMS pour l'Afrique, SAGO, UNFPA. Recommandations pour La Pratique Clinique Des soins obstétricaux 
et néonataux d'urgence en Afrique. 2010 http://sago.sante.gov.ml/ pdf2008/RPC\%20Interior9thproof.pdf.

11. Driessen M, Bouvier-Colle MH, Dupont C, et al. Postpartum hemorrhage resulting from uterine atony after vaginal delivery: factors sssociated with severity. Obstet Gynecol 2011;17:21-31.

12. Tort J, Traore M, Hounkpatin B, et al. Components of initial management associated with reduction of severe postpartum hemorrhage: a cohort study in Benin and Mali. Int J Gynaecol Obstet 2016;135:S84-8.

13. Burke TF, Ahn R, Nelson BD, et al. A postpartum haemorrhage package with condom uterine balloon tamponade: a prospective multi-centre case series in Kenya, Sierra Leone, Senegal, and Nepal. BJOG 2016;123:1532-40.

14. Diemert A, Ortmeyer G, Hollwitz B, et al. The combination of intrauterine balloon tamponade and the B-Lynch procedure for the treatment of severe postpartum hemorrhage. Am J Obstet Gynecol 2012;206:65.e1-e4.

15. Laas E, Bui C, Popowski T, et al. Trends in the rate of invasive procedures after the addition of the intrauterine tamponade test to a protocol for management of severe postpartum hemorrhage. Am J Obstet Gynecol 2012;207:281.e1-7.

16. Dildy GA, Belfort MA, Adair CD, et al. Initial experience with a dualballoon catheter for the management of postpartum hemorrhage. Am J Obstet Gynecol 2014;210:136.e1-e6.
17. Georgiou C. Intraluminal pressure readings during the establishment of a positive 'tamponade test' in the management of postpartum haemorrhage. BJOG 2010;117:295-303.

18. Darwish AM, Abdallah MM, Shaaban OM, et al. Bakri balloon versus condom-loaded Foley's catheter for treatment of atonic postpartum hemorrhage secondary to vaginal delivery: a randomized controlled trial. J Matern Fetal Neonatal Med 2017:1-7.

19. Aderoba AK, Olagbuji BN, Akintan AL, et al. Condom-catheter tamponade for the treatment of postpartum haemorrhage and factors associated with success: a prospective observational study. BJOG 2016.

20. Chong YS, Chua S, El-Refaey H, et al. Postpartum intrauterine pressure studies of the uterotonic effect of oral misoprostol and intramuscular syntometrine. BJOG 2001;108:41-7.

21. Prata N, Weidert K. Efficacy of misoprostol for the treatment of postpartum hemorrhage: current knowledge and implications for health care planning. Int $J$ Womens Health 2016;8:341-9.

22. Hofmeyr GJ, Gülmezoglu AM, Novikova N, et al. Misoprostol to prevent and treat postpartum haemorrhage: a systematic review and meta-analysis of maternal deaths and dose-related effects. Bull World Health Organ 2009;87:666-7. 